\title{
Simultaneous presence of two different copies of the 16S rRNA gene in Bartonella henselae
}

Correspondence

Mardjan Arvand

mardjan.arvand@med.

uni-rostock.de

Received 18 March 2008

Revised 15 May 2008

Accepted 22 May 2008

\author{
Juliane Viezens and Mardjan Arvand
}

Institut für Medizinische Mikrobiologie, Virologie und Hygiene, Universität Rostock, D-18057

Rostock, Germany

\begin{abstract}
Bartonella henselae is an emerging pathogen of increasing medical significance. Previous investigations have revealed two different 16S rRNA gene variants among $B$. henselae isolates, resulting in delineation of the $B$. henselae population into 16S RNA type I and type II isolates. While studying $191 \mathrm{~B}$. henselae isolates by multi-locus sequence typing (MLST) we detected three isolates that could not be assigned to a distinct 16S RNA type upon direct sequencing because of ambiguous nucleotides in a distinct region of the 16S rRNA gene. Cloning and sequencing of the target region of the 16S rRNA gene suggested that these atypical isolates contained different $16 \mathrm{~S}$ rRNA gene copies. Southern blot and hybridization experiments confirmed the presence of two different 16S RNA gene copies in each isolate. The isolates were further analysed by 16S RNA type-specific PCR, which assigned them to both 16S RNA types I and II. These results suggest that a small percentage of $B$. henselae isolates may harbour two different $16 \mathrm{~S}$ rRNA gene copies. These isolates, which accounted for $1.6 \%$ of the isolates in our study, have probably emerged by horizontal gene transfer. The implications of these findings for identification and genotyping studies on $B$. henselae are discussed.
\end{abstract}

\section{INTRODUCTION}

Bartonella henselae is the causative agent of a wide variety of infectious diseases including cat scratch disease, bacillary angiomatosis, prolonged fever ('fever of unknown origin'), and endocarditis (Spach \& Koehler, 1998). Domestic cats represent the main host and reservoir for $B$. henselae. Infected cats develop a relapsing bacteraemia of several months' duration during which $B$. henselae may be transmitted to other cats or humans by Ctenocephalides felis (cat flea) or cat scratch or bite injuries.

Identification of Bartonella species is usually based on molecular methods rather than biochemical reactions because of the fastidious and relatively inert nature of bartonellae. Analysis of the nucleotide sequence of the $16 \mathrm{~S}$ rRNA gene was the first molecular method used for the identification of B. henselae (Relman et al., 1990). Bergmans et al. (1996) detected a 3 bp difference between the partial $16 \mathrm{~S}$ rRNA sequences of clinical $B$. henselae isolates obtained from Dutch patients with cat scratch disease and divided the isolates into two distinct genotypes, 16S RNA type I and type II. Subsequently, isolates belonging to the 16S RNA types I or II were detected by different investigators in other countries (Birtles et al., 2002; Chang et al., 2002; Drancourt et al., 1996; Guptill et al., 2004; Melter et al., 2003; Sander et al., 1997). The 16S RNA types were designated 16S RNA

Abbreviation: ST, sequence type. alleles 1 and 2 and included in the MLST scheme for $B$. henselae (Iredell et al., 2003).

We have recently studied the molecular epidemiology of $B$. henselae isolates from different hosts and various geographical regions by MLST (Arvand et al., 2007). During that study and in subsequent investigations, a total of 191 B. henselae isolates were subjected to direct $16 \mathrm{~S}$ rRNA gene sequencing. Three of these isolates could not be assigned to a distinct 16S RNA type by direct sequencing because of ambiguous nucleotides within a circumscribed region of the 16S rRNA gene. We hypothesized that these isolates may harbour two different copies of the 16S rRNA gene within their genome, leading to ambiguous base sequences within and downstream of the variable region. The atypical isolates were characterized by cloning and sequencing of the $16 \mathrm{~S}$ rRNA gene, Southern blot analysis and hybridization, and type-specific 16S RNA-PCR, which has frequently been used in previous studies for discrimination of the $16 \mathrm{~S}$ RNA variants. Our results demonstrate that the atypical $B$. henselae isolates harbour two different copies of the $16 \mathrm{~S}$ rRNA gene in their genomes.

\section{METHODS}

Bartonella isolates. A total of 191 feline and human B. henselae isolates from Europe, Australia and the USA were analysed. The epidemiological data of 184 isolates have been described previously (Arvand et al., 2007). The B. henselae isolates Ber-K186, Is-479 and 
Simba were isolated from blood cultures of naturally infected cats in Germany, Israel and the USA, respectively. The isolates were stored at $-20{ }^{\circ} \mathrm{C}$ or $-80{ }^{\circ} \mathrm{C}$ until use. Bacteria were grown on Columbia blood agar with $5 \%$ sheep blood at $37{ }^{\circ} \mathrm{C}$ in $5 \% \mathrm{CO}_{2}$ for $7-14$ days. A single colony of each isolate was passaged once on agar prior to isolation of bacterial DNA.

Direct 16S rRNA sequencing and MLST analysis. Partial sequences of eight genetic loci (16S rRNA, batR, gltA, groEL, ftsZ, $n l p D$, $r i b C$ and $r p o B$ ) were determined by direct sequencing on both strands as described before (Arvand \& Viezens, 2007; Iredell et al., 2003). The nucleotide sequences were analysed with the DNASTAR Lasergene software package 7 . The isolates were assigned to alleles and sequence types (STs) as described previously (Arvand et al., 2007).

Cloning and sequencing of the 16S rRNA gene. A 512 bp region of the $16 \mathrm{~S}$ rRNA gene was amplified by PCR using the primers $16 \mathrm{~S}-\mathrm{F}$ (5'-AGAGTTTGATCCTGGYTCAG-3') and 16S-R (5'-CTTTACGCCCARTAAWTCCG-3'), which were originally described by Bergmans et al. (1996). Cloning was performed using the TOPO TA Cloning kit with the pCR2.1-TOPO vector (Invitrogen) in Escherichia coli; 5-9 clones of each isolate were sequenced (GATC Biotech).

Southern blotting and hybridization. Bacteria were embedded in SeaPlaque GTG agarose and DNA was prepared following treatment with proteinase $\mathrm{K}$ and lysozyme as described for PFGE analysis (Arvand et al., 1998). The bacterial DNA was digested with HincII, or with HindIII and Eco81I simultaneously, at $37^{\circ} \mathrm{C}$ according to the manufacturer's instructions. All restriction enzymes were purchased from Fermentas. Restriction digests were separated by electrophoresis in a $0.8 \%$ agarose gel and transferred to a Biodyne B nylon membrane (Pall Gelman) by vacuum blotting. A DNA probe which was complementary to a 183 bp region of the $B$. henselae $16 \mathrm{~S}$ rRNA gene corresponding to bases $1414428-1414610$ of the $B$. henselae strain Houston-1 sequence (accession no. BX897699) was designed using the primers $16 \mathrm{~S}-\mathrm{F}$ and BH1 (5'-CCGATAAATCTTTCTCCCTAA-3'). The probe was labelled with dUTP by using the DIG Oligonucleotide Tailing kit (Roche Diagnostics). Hybridization was performed at $70{ }^{\circ} \mathrm{C}$ overnight and detection was performed with the CSPD chemiluminescence system (Roche Diagnostics). The $B$. henselae isolates Houston-1 (type I), Berlin-1 (type I), Urlly8 Marseille (type
II), Berlin-2 (type II) and Audrey (type II) were included in different experiments as controls.

165 RNA type-specific PCR assay. Type-specific PCR was performed using the primers $16 \mathrm{~S}-\mathrm{F}$ and $\mathrm{BH} 1$ or $\mathrm{BH} 25^{\prime}$ CCGATAAATCTTTCTCCAAAT-3') as described previously (Bergmans et al., 1996; Sander et al., 1998). Briefly, amplification was carried out in a $50 \mu \mathrm{l}$ reaction volume with $3 \mathrm{~min}$ at $95{ }^{\circ} \mathrm{C}, 30$ cycles of $20 \mathrm{~s}$ at $95{ }^{\circ} \mathrm{C}, 30 \mathrm{~s}$ at $57{ }^{\circ} \mathrm{C}$ (primers $16 \mathrm{~S}-\mathrm{F}$ and $\mathrm{BH} 1$ ) or $56{ }^{\circ} \mathrm{C}$ (primers $16 \mathrm{~S}-\mathrm{F}$ and $\mathrm{BH} 2$ ), $60 \mathrm{~s}$ at $72{ }^{\circ} \mathrm{C}$, and a final extension of $5 \mathrm{~min}$ at $72{ }^{\circ} \mathrm{C}$. The products were separated by electrophoresis in $2 \%$ agarose, stained with ethidium bromide, and photographed.

\section{RESULTS}

\section{Evidence for different 16S rRNA gene copies in a distinct $B$. henselae isolate by direct 16S rRNA gene sequencing}

During the analysis of $191 \mathrm{~B}$. henselae isolates by MLST, we could successfully determine the partial $16 \mathrm{~S}$ rRNA gene sequence of 188 isolates on both strands by direct sequencing. However, we could not obtain $16 \mathrm{~S}$ rRNA gene sequences of the appropriate length for the $B$. henselae isolates Ber-K186, IS-479 and Simba. Although the sequences were clear and of high quality at the beginning of both strands, they became undecipherable after approximately $150 \mathrm{bp}$ in the forward or $320 \mathrm{bp}$ in the reverse strand and remained unclear thereafter (Fig. 1). Therefore, we could not obtain overlapping sequences for those isolates.

\section{Cloning and sequencing of the 16S rRNA gene reveals two different 165 rRNA gene copies in the atypical isolates}

To determine the 16S rRNA gene sequences of the isolates Ber-K186, IS-479 and Simba, the 16S rRNA gene was

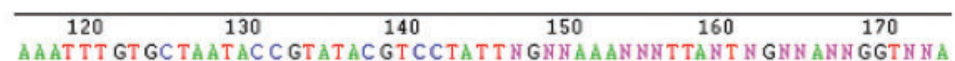

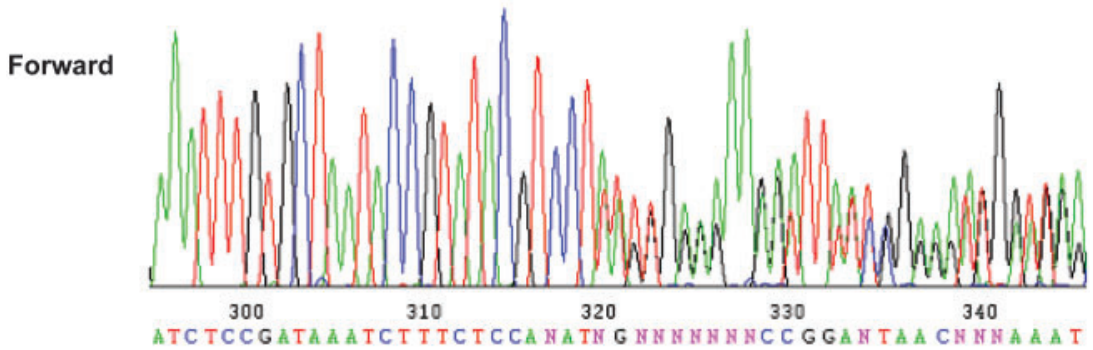

Reverse

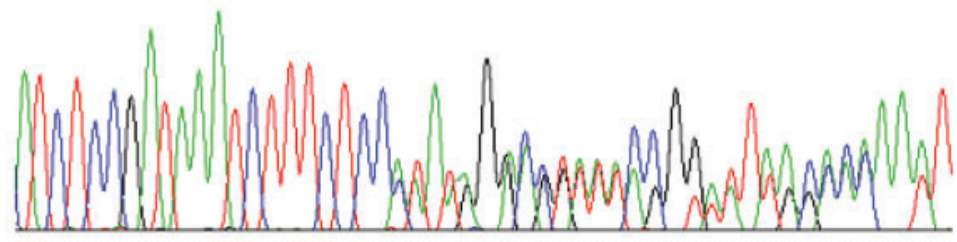

Fig. 1. Representative results of direct sequencing of the 16S rRNA gene of the $B$. henselae isolate Is-479. The sequences, obtained using the primers 16S-F (forward) and 16S-R (reverse), show an abrupt onset of ambiguous bases that is suggestive of overlapping sequences. 
amplified by PCR, cloned in E. coli, and 5-9 clones from each isolate were sequenced. Two or more clones obtained from each isolate contained the 16S RNA allele 1, corresponding to the $16 \mathrm{~S}$ rRNA gene sequence of $B$. henselae Houston-1 (accession no. BX897699), whereas other clones obtained from the same isolate contained the $16 \mathrm{~S}$ RNA allele 2, corresponding to the $16 \mathrm{~S}$ rRNA gene sequence of B. henselae Urlly8 (accession no. AF214556). The sequences of alleles 1 and 2 differed in three nucleotides including a gap. In detail, the nucleotides CTA- in allele 1 corresponding to the position 14144451414447 and 1584454-1584456 of the B. henselae Houston1 sequence (accession no. BX897699) were replaced by AAAT in allele 2. These results suggest that the atypical isolates possess two different copies of the 16S rRNA gene.

\section{Determination of the copy number of the 165 rRNA gene by Southern blotting and hybridization}

To determine the copy number of the 16S rRNA gene in the atypical isolates, chromosomal DNA of these isolates and reference strains was digested with HincII, which does not cleave within the 16S rRNA gene. The estimated size of the restriction digests that would contain the 16S RNA genes was 4110 and $4723 \mathrm{bp}$, as deduced from the sequence of the $B$. henselae Houston-1 strain. Hybridization was performed with a 183 bp $16 \mathrm{~S}$ rRNA gene-specific probe. The isolates Ber-K186, IS-479 and Simba, and the reference strains Houston-1 and Urlly8, revealed two fragments, of approximately 4.1 and $4.7 \mathrm{~kb}$ (data not shown), indicating that all isolates harboured two copies of the 16S rRNA gene.

\section{Evidence for two different 165 rRNA copies in a distinct $B$. henselae isolate by double digestion and Southern blotting}

To confirm the presence of different $16 \mathrm{~S}$ rRNA gene copies in the isolates Ber-K186, Is-479 and Simba, genomic DNA was subjected to double digestion with HindIII and Eco81I. The former enzyme has no restriction site within the $16 \mathrm{~S}$ rRNA gene. Restriction of $B$. henselae DNA with HindIII should generate two fragments of approximately 3.7 and $2.7 \mathrm{~kb}$ that harbour the $16 \mathrm{~S}$ rRNA gene copies, as deduced from the genome sequence of the Houston-1 isolate. Eco81I possesses a recognition site within the $16 \mathrm{~S}$ RNA allele 1, but not in allele 2. Digestion of chromosomal DNA of a type I isolate with HindIII and Eco81I would yield four fragments, three of approximately $1.8 \mathrm{~kb}$ and one of approximately $0.8 \mathrm{~kb}$, which contain the restriction fragments of the $16 \mathrm{~S}$ rRNA gene. In contrast, digestion of chromosomal DNA of type II isolates with HindIII and Eco81I would yield two fragments of approximately 3.7 and $2.7 \mathrm{~kb}$ that harbour the two 16S rRNA gene copies. We hypothesized that the isolates with two different $16 \mathrm{~S}$ rRNA gene copies would reveal a combination of type I and II patterns, presented schematically in Fig. 2(a) as option 1 and option 2. Hybridization was performed with the 183 bp 16S rRNAspecific probe as described above. As shown in Fig. 2(b), the isolates Ber-K186, Is-479 and Simba displayed a combined 'type I and II' pattern corresponding to option 2. In contrast, the reference strains Houston-1, which has 16S RNA allele 1, and Urlly8 and Audrey, which have 16S RNA allele 2, showed representative restriction patterns for type I or type II isolates, respectively.

\section{Isolates with different 16S rRNA gene copies are assigned to both genotypes by 16S RNA type- specific PCR}

16S RNA type-specific PCR has frequently been used to determine the 16S RNA genotype of $B$. henselae isolates (Guptill et al., 2004; Gurfield et al., 1997; Melter et al., 2003; Maruyama et al., 2001; Matar et al., 1999; Sander et al., 1997). We therefore tested whether the atypical $B$. henselae isolates could be assigned to a distinct 16S RNA type by using this assay. The isolates Ber-K186, Is-479 and

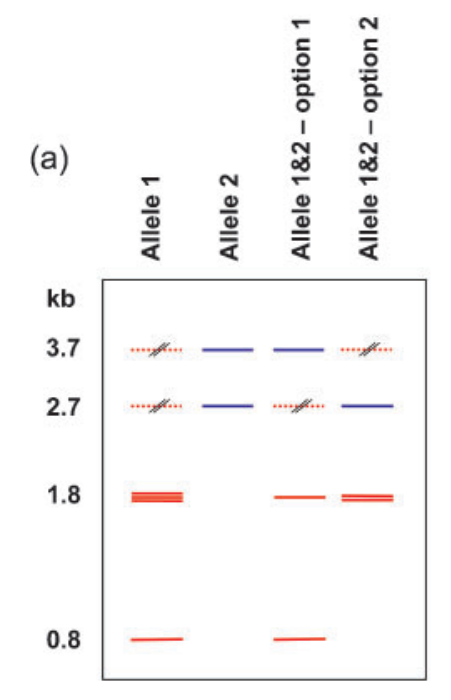

(b)

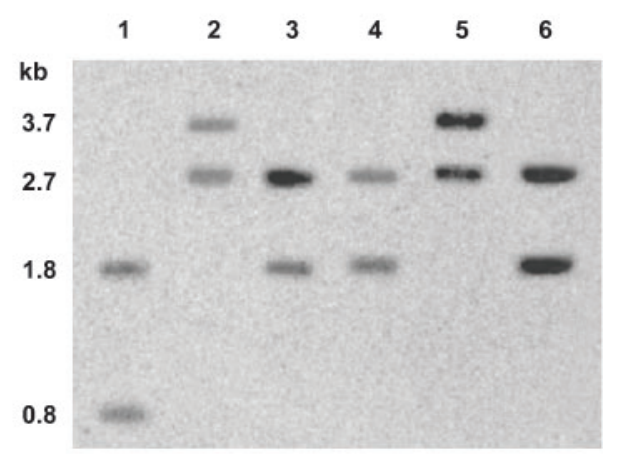

Fig. 2. Southern blot analysis of $B$. henselae DNA after double digestion with Hindlll and Eco81l. (a) Expected size of restriction fragments containing the 16S rRNA genes of isolates with two copies of the 16S RNA allele 1 (red lines) or allele 2 (blue lines), or one copy of each allele. (b) Restriction fragments of $B$. henselae isolates: lane 1, Houston-1 (type I); lane 2, Urlly8 (type II); lane 3, Ber-K186; lane 4, Is-479; lane 5, Audrey (type II); lane 6, Simba. 
Simba were subjected to $16 \mathrm{~S}$ RNA type-specific PCR along with reference strains. The isolates with different $16 \mathrm{~S}$ rRNA gene copies revealed positive results in both type I- and type II-specific PCR (Fig. 3). In contrast, the reference strains revealed a positive result in either type I- or type IIspecific PCR. Thus, $B$. henselae isolates with two different 16S RNA alleles are recognized as double-positive isolates by the type-specific PCR assay.

\section{Allelic profiles of isolates with different 16S rRNA gene copies by MLST}

The allelic profiles of the isolates Ber-K186, Is-479 and Simba are presented in Table 1. They differed in one or more positions from each other, indicating that the isolates did not belong to the same ST. Since $16 \mathrm{~S}$ rRNA is one of the genes included in the MLST scheme of $B$. henselae (Iredell et al., 2003), the isolates with different 16S rRNA gene copies could not be assigned to any ST.

\section{DISCUSSION}

Presence of multiple copies of the 16S rRNA gene has been documented for several bacterial species (Acinas et al., 2004). Generally, multiple copies of rRNA genes in an organism are either identical or nearly identical in nucleotide sequence. Recent reports have shown that within some species, the multiple rRNA gene copies may show distinct sequence differences (Conville \& Witebsky, 2005, 2007; Ninet et al., 1996; Reischl et al., 1998; Wang et al., 1997). Sequence diversity of the $16 \mathrm{~S}$ rRNA gene in $B$. henselae was first described in 1996 (Bergmans et al., 1996). Two 16S RNA variants were detected among $B$. henselae isolates: type I represented by the Houston-1 strain, and type II represented by the Urlly8 and the Berlin-2 strain (Arvand et al., 2001; Drancourt et al., 1996). The delineation of $B$. henselae isolates into two 16S RNA types
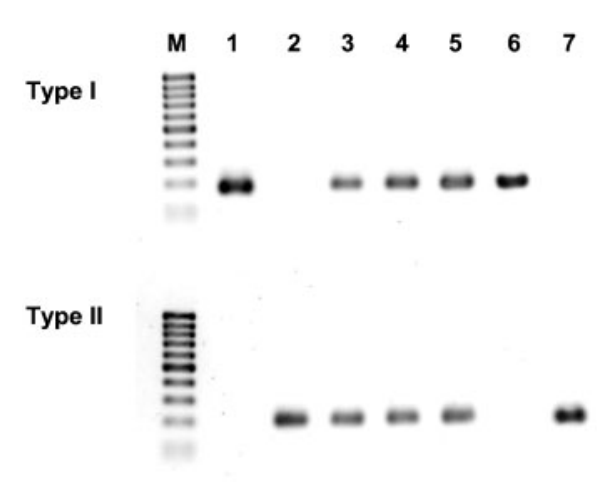

Fig. 3. $16 \mathrm{~S}$ RNA type-specific PCR. $\mathrm{M}, 100 \mathrm{~kb}$ molecular mass marker; lane 1, B. henselae Houston-1 (type I); lane 2, Urlly8 (type II); lane 3, Ber-K186; lane 4, Is-479; lane 5, Simba; lane 6, Berlin1 (type I); lane 7, Berlin 2 (type II).
Table 1. Allelic profiles of the $B$. henselae isolates with two different 16S rRNA gene copies

The sequences of all alleles have been previously described (Arvand et al., 2007).

\begin{tabular}{|lccccccccc|}
\hline Isolate & 16S rRNA & batR & gltA & groEL & ftsZ & nlpD & ribC $\boldsymbol{r p o B}$ \\
\hline Ber-K186 & 1 and 2 & 3 & 2 & 2 & 2 & 1 & 1 & 2 \\
Is-479 & 1 and 2 & 1 & 1 & 2 & 1 & 1 & 1 & 1 \\
Simba & 1 and 2 & 1 & 1 & 1 & 1 & 1 & 1 & 1 \\
\hline
\end{tabular}

has been frequently used in previous studies and is also part of the MLST scheme for B. henselae (Chang et al., 2002; Guptill et al., 2004; Heller et al., 1997; Iredell et al., 2003; Maruyama et al., 2001; Melter et al., 2003). Recently, the complete genome sequence of the $B$. henselae Houston1 strain became available and was shown to contain two identical copies of the 16S rRNA gene (Alsmark et al., 2004). In the present study, we demonstrate, we believe for the first time, the presence of two different $16 \mathrm{~S}$ rRNA gene copies in the genomes of individual $B$. henselae isolates.

The $B$. henselae isolates with different $16 \mathrm{~S}$ rRNA gene copies were detected during a study on molecular epidemiology of $B$. henselae isolates from different hosts and geographical regions by MLST. The atypical isolates were originally isolated from distinct hosts in different countries and were therefore not epidemiologically related. The MLST allelic profiles of these isolates displayed one or more allelic differences, indicating that they were also not very closely related genetically. We conclude that our isolates with different $16 \mathrm{~S}$ rRNA gene copies are not clonally related but rather have emerged independently from each other. A possible mechanism for the emergence of isolates with two different 16S RNA alleles is horizontal gene transfer. This could possibly occur when an arthropod vector or a feline host is simultaneously infected with different $B$. henselae strains harbouring distinct alleles. Other possible mechanisms such as mutation are less likely because the two alleles of the 16S RNA gene differ from each other in three nucleotides, which would require three simultaneous mutations at distinct positions within the $16 \mathrm{~S}$ rRNA gene copy.

Theoretically, a hybrid-type isolate with two different $16 \mathrm{~S}$ RNA copies may display two different genomic arrangements with allele 1 at position 1413128-1414619 and allele 2 at position $1583137-1584628$ of the B. henselae Houston1 sequence (accession no. BX897699), and vice versa. Restriction of these variants with HindIII and Eco81I would result in patterns presented as options 1 and 2 in Fig. 2(a). It is interesting that all three hybrid isolates detected in this study corresponded to option 2. Because of the limited number of the hybrid isolates in this study, we can only speculate whether this finding is a simple coincidence. Future studies on more hybrid isolates would help to elucidate this question. 
The presence of two different 16S rRNA gene copies in a distinct $B$. henselae isolate has implications for future studies on $B$. henselae and probably other Bartonella species. When 16S rRNA gene sequencing is used for identification of Bartonella-like organisms to the species level, the investigators should be aware of the possibility that some $B$. henselae isolates may harbour different $16 \mathrm{~S}$ rRNA gene copies, which might lead to equivocal nucleotide sequences by direct sequencing. Furthermore, it is possible that some previously described cases of double infection of a distinct host by two $B$. henselae isolates of $16 \mathrm{~S}$ RNA types I and II, which were diagnosed by 16S RNA type-specific PCR, were in reality caused by a single isolate that harboured both 16S RNA alleles. It would be useful to subject those isolates to additional tests, e.g. direct sequencing of the 16S rRNA gene, MLST analysis or other genotyping methods, in order to differentiate between simultaneous infection by two different isolates and infection by one isolate that harbours two different copies of the 16S rRNA gene.

In summary, our data indicate that a small percentage of $B$. henselae isolates harbour two different copies of the $16 \mathrm{~S}$ rRNA gene. These isolates have probably emerged by horizontal gene transfer. Investigators involved in sequence-based identification or typing of $B$. henselae should be aware of the existence of such atypical isolates.

\section{ACKNOWLEDGEMENTS}

This project was supported by the FORUN programme of the University of Rostock and grant AR323/3 of the Deutsche Forschungsgemeinschaft to M.A. We thank Yvonne Humboldt for excellent technical assistance, and Drs Lynn Guptill and Michael Giladi for providing $B$. henselae isolates.

\section{REFERENCES}

Acinas, S. G., Marcelino, L. A., Klepac-Ceraj, V. \& Polz, M. F. (2004). Divergence and redundancy of $16 \mathrm{~S}$ rRNA sequences in genomes with multiple rrn operons. J Bacteriol 186, 2629-2635.

Alsmark, C. M., Frank, A. C., Karlberg, E. O., Legault, B. A., Ardell, D. H., Canbäck, B., Eriksson, A. S., Näslund, A. K., Handley, S. A. \& other authors (2004). The louse-borne human pathogen Bartonella quintana is a genomic derivative of the zoonotic agent Bartonella henselae. Proc Natl Acad Sci U S A 101, 9716-9721.

Arvand, M. \& Viezens, J. (2007). Evaluation of pulsed-field gel electrophoresis and multi-locus sequence typing for the analysis of clonal relatedness among Bartonella henselae isolates. Int $\mathrm{J}$ Med Microbiol 297, 255-262.

Arvand, M., Wendt, C., Regnath, T., Ullrich, R. \& Hahn, H. (1998). Characterization of Bartonella henselae isolated from bacillary angiomatosis lesions in a human immunodeficiency virus-infected patient in Germany. Clin Infect Dis 26, 1296-1299.

Arvand, M., Klose, A. J., Schwartz-Porsche, D., Hahn, H. \& Wendt, C. (2001). Genetic variability and prevalence of Bartonella henselae in cats in Berlin, Germany, and analysis of its genetic relatedness to a strain from Berlin that is pathogenic for humans. J Clin Microbiol 39, $743-746$.
Arvand, M., Feil, E. J., Giladi, M., Boulouis, H. J. \& Viezens, J. (2007). Multi-locus sequence typing of Bartonella henselae isolates from three continents reveals hypervirulent and feline-associated clones. PLoS ONE 2, e1346.

Bergmans, A. M., Schellekens, J. F., van Embden, J. D. \& Schouls, L. M. (1996). Predominance of two Bartonella henselae variants among cat-scratch disease patients in the Netherlands. J Clin Microbiol 34, 254-260.

Birtles, R. J., Laycock, G., Kenny, M. J., Shaw, S. E. \& Day, M. J. (2002). Prevalence of Bartonella species causing bacteraemia in domesticated and companion animals in the United Kingdom. Vet Rec 151, 225-229.

Chang, C. C., Chomel, B. B., Kasten, R. W., Tappero, J. W., Sanchez, M. A. \& Koehler, J. E. (2002). Molecular epidemiology of Bartonella henselae infection in human immunodeficiency virus-infected patients and their cat contacts, using pulsed-field gel electrophoresis and genotyping. J Infect Dis 186, 1733-1739.

Conville, P. S. \& Witebsky, F. G. (2005). Multiple copies of the $16 \mathrm{~S}$ rRNA gene in Nocardia nova isolates and implications for sequencebased identification procedures. J Clin Microbiol 43, 2881-2885.

Conville, P. S. \& Witebsky, F. G. (2007). Analysis of multiple differing copies of the $16 \mathrm{~S}$ rRNA gene in five clinical isolates and three type strains of Nocardia species and implications for species assignment. J Clin Microbiol 45, 1146-1151.

Drancourt, M., Birtles, R., Chaumentin, G., Vandenesch, F., Etienne, J. \& Raoult, D. (1996). New serotype of Bartonella henselae in endocarditis and cat-scratch disease. Lancet 347, 441-443.

Guptill, L., Wu, C. C., Hogenesch, H., Slater, L. N., Glickman, N., Dunham, A., Syme, H. \& Glickman, L. (2004). Prevalence, risk factors, and genetic diversity of Bartonella henselae infections in pet cats in four regions of the United States. J Clin Microbiol 42, 652-659.

Gurfield, A. N., Boulouis, H. J., Chomel, B. B., Heller, R., Kasten, R. W., Yamamoto, K. \& Piemont, Y. (1997). Coinfection with Bartonella clarridgeiae and Bartonella henselae and with different Bartonella henselae strains in domestic cats. J Clin Microbiol 35, 2120-2123.

Heller, R., Artois, M., Xemar, V., De Briel, D., Gehin, H., Jaulhac, B., Monteil, H. \& Piemont, Y. (1997). Prevalence of Bartonella henselae and Bartonella clarridgeiae in stray cats. J Clin Microbiol 35, 1327-1331.

Iredell, J., Blanckenberg, D., Arvand, M., Grauling, S., Feil, E. J. \& Birtles, R. J. (2003). Characterization of the natural population of Bartonella henselae by multilocus sequence typing. J Clin Microbiol 41, 5071-5079.

Maruyama, S., Sakai, T., Morita, Y., Tanaka, S., Kabeya, H., Boonmar, S., Poapolathep, A., Chalarmchaikit, T., Chang, C. C. \& other authors (2001). Prevalence of Bartonella species and 16S rRNA gene types of Bartonella henselae from domestic cats in Thailand. Am J Trop Med Hyg 65, 783-787.

Matar, G. M., Koehler, J. E., Malcolm, G., Lambert-Fair, M. A., Tappero, J., Hunter, S. B. \& Swaminathan, B. (1999). Identification of Bartonella species directly in clinical specimens by PCR-restriction fragment length polymorphism analysis of a $16 \mathrm{~S}$ rRNA gene fragment. J Clin Microbiol 37, 4045-4047.

Melter, O., Hercik, K., Weyant, R. S., Janecek, J., Nemec, A., Mecera, J., Gonzorova, L. \& Branny, P. (2003). Detection and characterization of feline Bartonella henselae in the Czech Republic. Vet Microbiol 93, 261-273.

Ninet, B., Monod, M., Emler, S., Pawlowski, J., Metral, C., Rohner, P., Auckenthaler, R. \& Hirschel, B. (1996). Two different 16S rRNA genes in a mycobacterial strain. J Clin Microbiol 34, 2531-2536.

Reischl, U., Feldmann, K., Naumann, L., Gaugler, B. J., Ninet, B., Hirschel, B. \& Emler, S. (1998). 16S rRNA sequence diversity in Mycobacterium celatum strains caused by presence of two different copies of 16S rRNA gene. J Clin Microbiol 36, 1761-1764. 
Relman, D. A., Loutit, J. S., Schmidt, T. M., Falkow, S. \& Tompkins, L. S. (1990). The agent of bacillary angiomatosis. An approach to the identification of uncultured pathogens. N Engl J Med 323, 1573-1580.

Sander, A., Buhler, C., Pelz, K., von Cramm, E. \& Bredt, W. (1997). Detection and identification of two Bartonella henselae variants in domestic cats in Germany. J Clin Microbiol 35, 584-587.

Sander, A., Ruess, M., Bereswill, S., Schuppler, M. \& Steinbrueckner, B. (1998). Comparison of different DNA fingerprinting techniques for molecular typing of Bartonella henselae isolates. J Clin Microbiol 36, 2973-2981.

Spach, D. H. \& Koehler, J. E. (1998). Bartonella-associated infections. Infect Dis Clin North Am 12, 137-155.

Wang, Y., Zhang, Z. \& Ramanan, N. (1997). The actinomycete Thermobispora bispora contains two distinct types of transcriptionally active $16 S$ rRNA genes. J Bacteriol 179, 3270-3276.

Edited by: P. E. Everest 